\title{
Sesc-SP: educação permanente, diversão garantida
}

Resumo: O diretor regional do Sesc-SP, Danilo Santos de Miranda, responsável direto pela política cultural de ponta incrementada no estado de São Paulo, é uma figura expressiva no cenário dos profissionais gestores na área da cultura, pois tem conseguido formular, com sua equipe, uma política de comprovada excelência. Nesta entrevista, ele relata a bem-sucedida experiência da instituição com a educação não formal e avalia a importância da comunicação para a educação.

Palavras-chave: Sesc, indústria, comércio, educação, cultura.
Abstract: The regional director of the Sesc/ SP, Danilo Santos de Miranda, is a leading person in the scenery of cultural managers and directly responsible for the innovative policy implemented by his institution in the state of São Paulo. In this interview, he reports his institution's well succeeded experience in non-formal education and evaluates the importance of communication for education.

Keywords: Sesc, industry, commerce, education, culture.

Filósofo e cientista social, com especialização em Recursos Humanos, Danilo Santos de Miranda é diretor regional do Sesc-SP há 23 anos. Administra uma equipe de mais de 6 mil pessoas nas 31 unidades do estado, promovendo atividades de bem-estar social. A entidade está presente em 26 estados e no Distrito Federal. O Serviço Social do Comércio (Sesc), criado em setembro de 1946, é mantido por empresários do comércio de bens e serviços e atua nas áreas de educação, saúde, lazer, cultura e assistência. Por ano, atende cerca de 3 milhões e 600 mil pessoas nas ações sociais da entidade, além de cuidar de produção cultural, crescimento do turismo, conscientização ecológica e preservação ambiental. O Sesc oferece creche, educação infantil e de jovens e adultos, além de odontologia, medicina preventiva e apoio. Na cultura, coloca à disposição opções de cinema, teatro, música, artes plásticas, dança e artesanato. Nesta entrevista, Danilo Miranda conta aos leitores da C\&E como é possível manter um projeto permanente de educação através da cultura, sem deixar de garantir ao público um nível de excelência do lazer, uma ocupação adequada do tempo livre, e preocupado em transformar as pessoas.

Por Consuelo Ivo

C\&EE: Hoje, o maior problema do Brasil é a educação, e também a sua melhor solução. Como diretor regional do Sesc-SP e com uma reconhecida experiência com a educação informal, como você avalia este momento?

Danilo Miranda: Essa questão educacional brasileira é realmente fundamental. Diria que o problema é a educação mesmo. Através dela temos um caminho para 
comunicação \& educação • Ano XIV • Número 2 • maio/ago 2009

desenvolver uma sociedade mais adequada, mais justa, humana, resolvendo questões ligadas ao atendimento não apenas daquelas necessidades básicas da população, mas também as de aprimoramento e desenvolvimento. Não acredito em desenvolvimento econômico, em desenvolvimento puramente material, sem que o lado educacional, a preparação das pessoas, a melhoria de vida, estejam fundamentadas, bem colocadas. Quando penso em educação, penso-a voltada para determinado objetivo. Não em uma educação que transfira informação, que crie pessoas hábeis para desenvolver certo tipo de técnica ou capazes de resolver certos problemas, apenas. Penso no sentido mais básico, mais fundamental, que é o de prepará-las para uma vida autônoma, adulta, em que sejam aptas a tomar decisões, a entender o mundo a sua volta, a ter uma visão da sociedade na qual estão inseridas. Isso é o mais importante! $\mathrm{E}$ a partir daí, conseguimos entender todo o restante. Então, nesse sentido, a leitura do mundo, da sociedade, da realidade, enfim, das circunstâncias que nos envolvem, das razões por que estamos aqui, das perspectivas que nos fazem trabalhar em prol dos demais - esse componente ético que está presente no nosso dia a dia -, isso é fundamental para um processo educativo realmente efetivo. A escola tem seu papel, mas não só no sentido tradicional do ensino regular. E numa instituição como a nossa, e em muitas outras, como a dos meios de comunicação, do mundo do ensino, das artes, deve existir um compromisso com a educação. E não tem havido. Na prática, quem vem assumindo esse compromisso são as escolas, mesmo que de modo incompleto; porém, falta compreender a educação como processo permanente. Então, educação, para mim, tem a ver, sim, com escola, professor, aluno, sala de aula, em todos os níveis... Mas tem a ver também com a leitura da realidade do mundo a nossa volta. Estamos falando de educação num sentido muito mais profundo e completo, que é chamado de educação permanente, ou educação contínua ou informal. É aquela que começa quando o indivíduo vem ao mundo e só termina quando ele o deixa. Portanto, essa é a verdadeira questão educacional. E a cultura, a discussão sobre o papel da cultura, a informação sobre cultura, o envolvimento das pessoas com a questão cultural como um todo, é uma espécie de guarda-chuva que abrange tudo isso. Porque, quando estou falando de cultura, não me refiro só à educação regular, nem apenas à cultura das artes, mas da relação do ser humano com as coisas a sua volta, consigo mesmo, com seu corpo, e seu entendimento da realidade. Estou falando do meio ambiente, da sociedade, de tudo que faz parte desse mundo bastante amplo. E tudo que o homem construiu, constrói e vai construir, em todos os sentidos, em todos os âmbitos do conhecimento, possíveis e imagináveis, de acordo com os princípios básicos da sua visão antropológica, é cultura. Enquanto educação, claro, nesse sentido, é a passagem, é a comunicação de tudo isso. Ocorre num processo educacional regular, numa fase da vida da gente, de uma maneira mais intensa, mas ocorre também no decorrer de toda a nossa vida.

* Respectivamente, Serviço Social do Comércio, Serviço Nacional de Aprendizagem Comercial, Serviço Nacional de Aprendizagem Industrial, Serviço Social da Indústria. (N.E.)

C\&E: A abordagem do trabalho assistencial mudou radicalmente nas últimas décadas e o Terceiro Setor surgiu para cuidar de muitas dessas questões. Como foi a evolução da educação não formal dentro do Sesc?

Danilo: Na origem de nossas instituições, que alguns insistem em chamar de "Sistema S" (Sesc, Senac, Senai e Sesi)* - e eu, particularmente, recuso um 
pouco essa denominação, porque, no momento que designamos de forma unificada, juntamos num mesmo conceito instituições absolutamente diferentes, com objetivos, culturas, modos de agir e perspectivas diversos -, elas não foram pensadas na perspectiva de hoje. Ou seja, não estavam totalmente voltadas à questão da ação sociocultural como um componente indispensável para o ser humano, como parte quase essencial da função social, para transformar quem chega em pessoas integradas num processo produtivo, em todos os sentidos, não apenas capitalista, mas de participação efetiva, na busca de um padrão de bem-estar para si mesmo e para os outros. Para mim, esse é o resultado final: o bem-estar social para todos como objetivo central. Mas não foi isso que nos mobilizou à época. Nos anos de 1940, tivemos intuições,

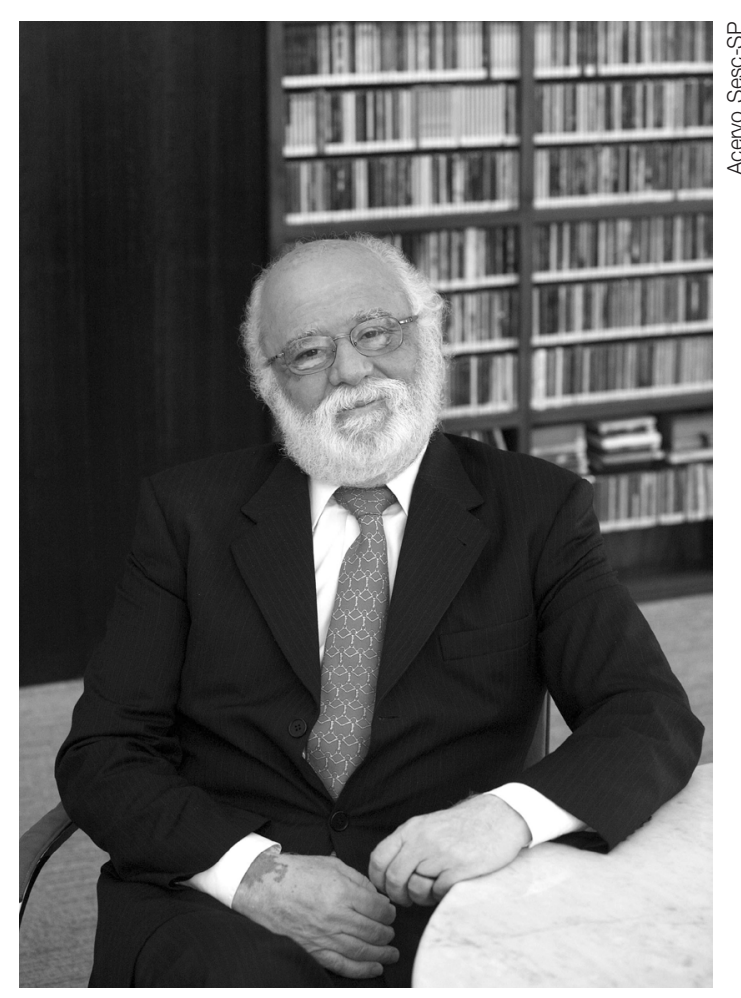

Danilo Santos de Miranda é diretor regional do Sesc-SP há 23 anos. Administra uma equipe de mais de 6 mil pessoas nas 31 unidades do Estado, promovendo atividades de bem-estar social. talvez por parte de alguns grandes nomes. Quando conceberam isso, já havia uma expectativa de que o Estado assumisse essa obrigação, o famoso welfare state, o Estado do Bem-Estar Social, mas não no Brasil. Aqui, a questão do pós-guerra era um momento muito especial. Havia um desejo de uma sociedade melhor, mais moderna, industrializada, saindo de um modelo bastante rural e atrasado, para um processo de industrialização e urbanização. E foi nessa hora que essas entidades surgiram, mas numa visão um pouco assistencialista mesmo, um pouco paternalista, diria. Os empresários bem resolvidos na vida, do ponto de vista econômico, social, político, educacional etc., resolveram destinar um pouco dos seus recursos, do resultado das suas operações - já que o Estado, na época, não teria condições de fazer isso -, para promover a sociedade e melhorar a vida das pessoas provenientes das camadas mais baixas, trabalhadores que vinham do mundo rural para o mundo urbano, para a indústria ou o comércio. E criaram essas entidades, inclusive para preparar mão de obra qualificada, como Senai e Senac, e também para o lado social, como Sesc e Sesi - as quatro originais. Essas entidades foram descobrindo, percebendo - por uma série de razões, como questões históricas, aprofundamento da discussão, evolução da própria sociedade, interesse dos dirigentes, necessidade de preparar uma comunidade técnica adequada -, o papel que teriam na construção de uma sociedade. E a base de sua ação passou a ser, não mais esse componente assistencialista de prover o que falta a quem necessita, mas de reconhecer direitos e desenvolver 
comunicação \& educação • Ano XIV • Número 2 - maio/ago 2009

nas pessoas a possibilidade de acesso. Quando falamos em direito ao acesso, não estamos mais nos referindo ao assistencialismo, mas em criar oportunidades para que isso surja, para cumprir direitos e abrir oportunidades. Para quê? Para uma vida melhor, social e culturalmente mais desenvolvida.

C\&E: As características regionais estabeleceram ações diferenciadas para o público-alvo, como o tempo livre do trabalhador?

Danilo: É verdade! É a teoria do lazer. Iniciamos de uma perspectiva um pouco assistencialista, e, na prática, o que era isso? Era prover saúde, alimentação, e até vestuário - é relacionado no nosso regulamento inicial -, bem como transporte. Tinha um pouco a ver com a instituição do operário-padrão, do socialismo real da antiga União Soviética, aquela coisa, meio: "Vamos ter trabalhadores exemplares, saúde, gente forte com capacidade para produzir muito”. E, claro, uma visão absolutamente equivocada sob muitos aspectos. Mas saímos dessa visão e partimos para uma concepção da questão do tempo livre, do lazer saudável e da cultura como parte desse processo de utilização do tempo livre como um componente de formação e melhoria de vida das pessoas. Fomos acertando o foco e chegando lá, graças a um fenômeno envolvendo os empresários e altos dirigentes, que permitiram e deram condição, lenha, para essa reflexão e essa conclusão: pessoas e preparação.

C\&E: E essas instituições não carregam a burocracia e o peso do Estado.

Danilo: Exatamente, e isso é fundamental, ou seja, o modelo dessas instituições é bem-sucedido porque parte da necessidade de se realizar com agilidade. Portanto, cumpre-se uma missão da matriz privada, mas daquela bem intencionada, a serviço dos seus objetivos, da sua clientela. E aí eu diria que ela tem uma função pública também, embora seja uma instituição privada, o que é um pouco a raiz, o fundamento do chamado Terceiro Setor.

\section{C\&E: Implica ainda Responsabilidade Social?}

Danilo: Sem dúvida, mas é preciso ficar claro que deve ser sempre resguardada a condição de instituições privadas e separadas do Estado. Essas entidades foram criadas para dividir o repasse de recursos privados voltados ao cultural e social, no caso Sesc e Sesi, e à formação profissional, como o Senac e o Senai. Assim, nossas entidades trazem um componente educacional que deve ser reconhecido.

C\&E: Esse reconhecimento leva outras instituições a procurarem orientação com vocês? Danilo: Muito. Nós recebemos, de praticamente todos os níveis de governo, convites para participar de discussões sobre ações públicas voltadas para questões como educação permanente, lazer, recreação e esporte inclusivo - aquele como componente educacional fundamental, diferente dos objetivos do esporte olímpico ou de resultados. E também direcionados a clientelas especiais, como crianças, adolescentes, adultos e idosos. Mantemos muito contato com secretarias e ministérios de esporte, cultura, educação, saúde, direitos humanos, para discutir questões ligadas ao direito das minorias, racial, do idoso... Enfim, uma temática extensa. Também produzimos diversos conteúdos e percebemos a importância 
de que esse material todo, em nossos variados âmbitos, seja canalizado em nossas edições. Agora temos uma editora própria, um selo para dar vazão à produção audiovisual a qual produzimos. Temos a TV Sesc para cumprir esse objetivo também. E tudo isso faz parte do esforço sempre em favor de uma perspectiva educacional. Não temos nada - é importante que

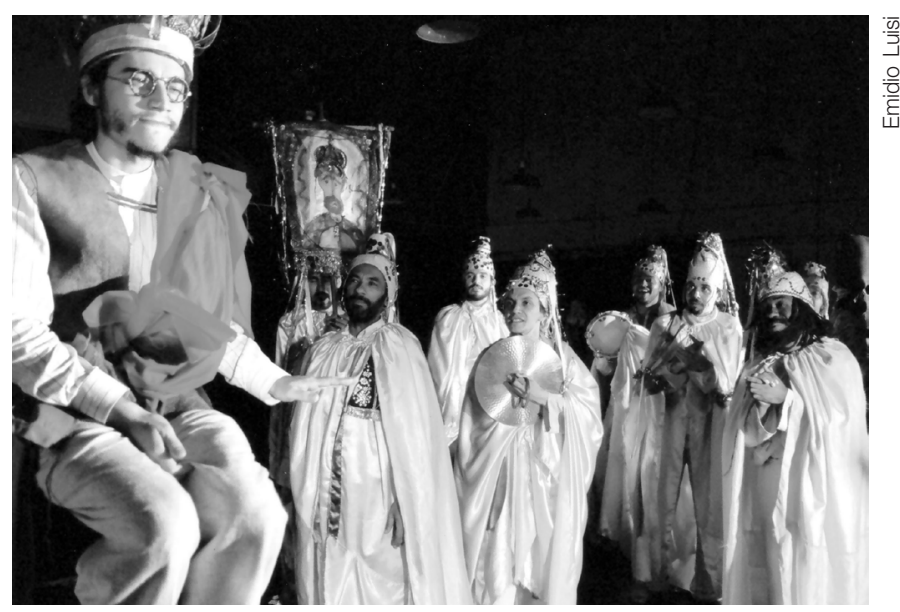

Lee Thalor interpreta Quaderna em A Pedra do Reino, montagem realizada pelo Grupo de Teatro Macunaíma e CPT (Centro de Pesquisa Teatral/Sesc-SP), apresentada nas unidades do Sesc-SP. se diga - contra a ação comercial, inclusive somos mantidos e pagos pelo comércio. Então, não nos poderíamos colocar numa situação de evitar ou condenar, mas nossa ação tem outro caráter e é diferente, portanto, mesmo com relação à indústria cultural. No nosso caso, o trabalho é uma produção de ordem institucional.

C\&E: A necessidade de implantar políticas públicas para a área de educação e cultura é uma realidade inquestionável. Quanto já avançamos?

Danilo: Acho uma necessidade fundamental. Tem ocorrido uma ampla discussão, talvez com a obrigação de uma visão mais clara do processo. No campo da educação, sem dúvida nenhuma, há o convencimento cada vez mais arraigado na sociedade da responsabilidade de todos com relação à educação. E quando falo de todos, estou me referindo também àqueles que não têm vínculo aparentemente direto com a educação, e não apenas a quem mantém um compromisso de ordem pública. Diria que até mesmo aqueles que possuem algum tipo de envolvimento com públicos, com pessoas, ou seja, todo mundo. Empresas privadas, públicas, não importa... igrejas, clubes, instituições, prestadores de serviços. En-

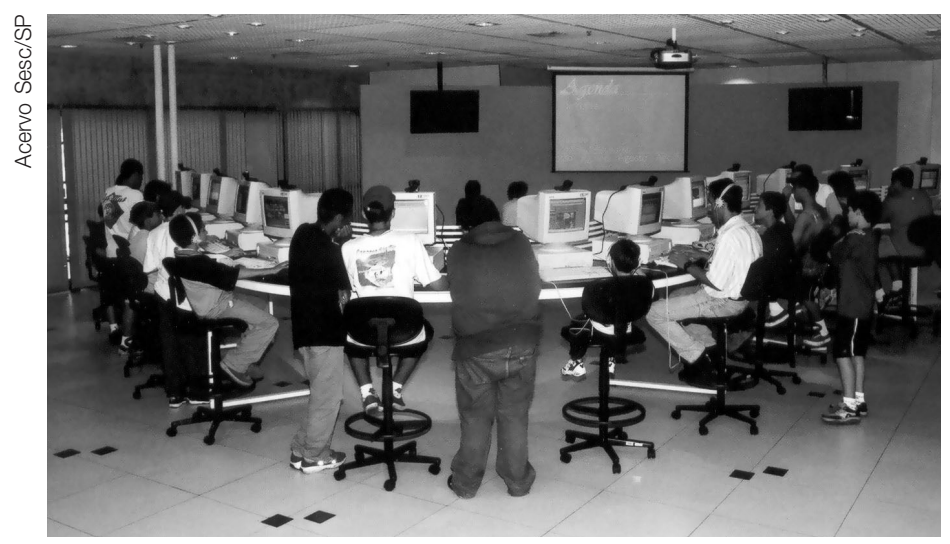

Internet Livre: o Sesc-SP dispõe de espaços equipados para a exploração das técnicas e conteúdos digitais, individualmente ou por meio de dinâmicas coletivas, em 24 unidades operacionais no Estado. fim, essa questão educacional tem de estar presente na sociedade como uma espécie de compromisso amplo e total, uma ideia permanente. Costumo dizer que a sociedade deve ter uma perspectiva educativa. Se tivesse que caracterizar uma sociedade, em vez de ela ser produtora de riqueza para usufruto 
comunicação \& educação • Ano XIV • Número 2 - maio/ago 2009

de seus membros, deveria ter um componente educativo em primeiro lugar. $\mathrm{O}$ resto viria naturalmente. Quando falo nesse componente educativo, a minha principal preocupação na vida tem a ver com aqueles que virão depois, ou seja, com aqueles que estão sendo preparados para dar continuidade a isso, e não simplesmente comigo, em como posso usufruir daquilo que está aqui, e acabou. Senão, vamos acabar com esse planeta em pouco tempo.

C\&E: Temos de estar preparados para oferecer essa formação?

Danilo: Isso para mim, do ponto de vista da educação, é claro. Um adulto diante do jovem, de uma criança, deve ter essa perspectiva sempre. Qualquer ato, comunicação, contato, tem que levar em conta isso. Atravessa a questão ética, digamos, do comportamento, enfim. Claro que sou um pouco utópico, mas acredito que devemos trabalhar na perspectiva da utopia. Ela não é a negação ou aquilo que nunca podemos atingir, mas o que ainda um dia pode acontecer. É uma negativa positiva, não uma negativa negativa. É a raiz grega ou+topos: lugar nenhum - topos -, o não lugar, mas é o lugar que pode acontecer, o devir. Essa é uma questão muito interessante e que deve sempre ser aprofundada. Agora, com relação à cultura, diria que cabe à sociedade preservar seus valores e criar novos. E a cultura tem uma discussão imensa com a questão dos valores. A administração pública tem obrigações tanto com a educação como com a cultura. Com a primeira, claramente no que diz respeito a sua estrutura educacional. E com a cultura, mais do que intervir, deve promover ações ligadas, sobretudo, às artes, à música, ao teatro, à dança etc. $\mathrm{O}$ que o poder público fundamentalmente teria de fazer seria elaborar políticas para que isso fosse mantido, para fomentar por parte da sociedade essas ações, essas linguagens de maneira bastante intensa, e não proibi-las, dificultá-las. O que isso quer dizer? Criar infraestrutura, fomento, é atividade educacional voltada para cultura.

C\&E: As atuais leis de incentivo são bastante criticadas pela interferência da publicidade e do marketing em suas regras e pela submissão do recurso público primeiro ao interesse mercadológico e não ao da sociedade.

Danilo: Essa é uma questão que estamos evoluindo, porque a percepção disso se torna cada vez mais clara. Se, de um lado, as leis de incentivo facilitam a utilização de recursos provenientes das empresas para determinadas ações, por outro, cria algumas confusões entre a chamada ação cultural com ação de publicidade, de marketing etc., mudando o foco sobre o beneficiado e o recurso. Não tem cabimento usar o recurso público para fazer propaganda. Em contrapartida, tem cabimento, sim, utilizá-lo com uma orientação de interesse público que seja proveniente de incentivo fiscal, de pagamento de impostos das empresas, para cumprir seus objetivos. Por que não? O ideal seria que isso não fosse necessário, que o Estado tivesse recursos suficientes, sem necessitar de incentivo, e cada um pagasse seus impostos justa e adequadamente. No entanto, temos uma supercarga tributária, incidindo sobre empresas e pessoas, e nem sempre existe o serviço correspondente àquilo que pagamos. 
Sesc-SP: educação permanente, diversão garantida • Consuelo Ivo

C\&E: Mas isso também não depende muito de quem quer fazer?

Danilo: É verdade! Acredito sempre que as leis, as organizações, possam ajudar e as políticas, colaborar. Mas sem a vontade, sem o envolvimento pessoal, sem as pessoas terem consciência do que estão fazendo, cumprindo seu papel, não vamos a lugar nenhum. Somos um país de leis relativamente boas, avançadas, mas a prática não tem correspondido às intenções de nossos legisladores. E nem mesmo eles, que são nossos representantes, têm cumprido com tanta eficácia, clareza, a própria lei.

C\&E: Muito do que desconhecemos é fruto também de uma desconstrução da nossa memória. O Sesc tem um projeto muito interessante. Como está o trabalho?

Danilo: O nosso centro de memória, o Projeto Memória, vem da constatação de que a nossa existência já é parte de uma história: iremos completar 63 anos em setembro. Acumulamos uma trajetória, sobre a qual em parte já contei aqui, de como a iniciamos e os rumos que demos à instituição. Criar um centro de memória significa reconhecer a importância de reunirmos todo esse cabedal de informações, de experiências, de imagens, enfim, de todo nosso material, e tentar organizá-lo de forma produtiva, tanto para o público interno como para aqueles que desejam fazer algum levantamento de pesquisa, de estudos sobre nós. Começamos a prepará-lo. Temos uma equipe que está se desdobrando em produzir produtos efetivos, como: futuras publicações sobre todo o nosso material; sobre a história das Unidades Móveis de Orientação Social (Unimos), que é uma fase importante vivida pelo Sesc nos anos 1970, e que, de alguma forma, influenciou a instituição até o presente; sobre todo o seu compromisso com determinadas posições, modos de fazer e de agir; sobre o respeito com a preparação de seus recursos humanos; sobre o investimento realizado na preparação das pessoas, no que diz respeito ao conhecimento...

C\&E: É preciso fazer primeiro a lição de casa?

Danilo: Sim, cumprir o papel de uma instituição que deseja apresentar propostas. E se você deseja isso, é necessário ser exemplar. Claro que parece um pouco pretensiosa tal afirmação, mas não adianta dizer: "Olha, queremos discutir a questão dos direitos humanos, da mulher, do negro etc.", se, dentro de casa, não cumprirmos essa missão. Não adianta falar de meio ambiente, de sustentabilidade, se não temos um programa interno que dê sustentação a essa proposta, e daí por diante. Não adianta só falar da importância da memória, da discussão dos nossos valores. Temos várias pesquisas, vários livros e publicações sobre essa questão da memória.

C\&E: Infelizmente, no Brasil, o que se percebe é um esforço para apagar sua memória. Danilo: Exatamente, sob todos os pontos de vista, mas especialmente aquilo que de alguma forma macula nosso passado. $\mathrm{E}$ temos de ter coragem de nos aprofundar, de levar às últimas consequências. É parte do processo, claro, mas isso sempre nos traz algumas considerações; por exemplo, a questão da escravidão. Fomos um dos últimos países a proibir, legalmente, a escravidão, embora tenhamos manifestações esporádicas até hoje, não só em nosso país, mas em 
comunicação \& educação • Ano XIV • Número 2 - maio/ago 2009

outras partes do mundo, de traços de comportamento escravocrata. Esse é um fato real da nossa vida, sem falar daquilo que permanece no nosso inconsciente coletivo, com relação à aceitação dos diferentes etc. Costumo dizer o seguinte: ter preconceito não é tão grave, porque, afinal, é fruto de educação, de influências etc. O problema é como lidar com ele, e não fazer nada para eliminá-lo. Isso é muito grave, claro! Se colocada fora do contexto, parece uma afirmação perigosa, mas sempre procuro expor de maneira muito transparente. Imagine uma criança cujos pais são preconceituosos em relação a isso ou aquilo, e a influenciam? Você vai responsabilizar a criança? Agora, depois de adulta, se continuar lidando da mesma forma com o problema, sem fazer qualquer esforço pessoal de enxergar o mundo como deve ser compreendido, aí a coisa muda de fato, e é preciso até lei para, diante de uma manifestação de preconceito, informá-la de que isso é crime.

C\&E: Como você vê a relação entre comunicação e educação?

Danilo: Não consigo entender, sinceramente, um conceito isolado de comunicação sem um componente educacional, e vice-versa. Explicando melhor, são duas noções absolutamente imbricadas, inerentes. É fundamental que haja esse esforço no sentido de compreender que o chamado mundo da comunicação - que ganhou uma dimensão avançadíssima do ponto de vista da tecnologia, da capacidade de obtermos qualquer informação na hora, no momento que se desejar, sobre aquilo que se quiser -, realmente, revolucionou o processo de comunicação e de educação. Por quê? Educação é informação, criação de valores, de hábitos digamos -, de atitudes, que faz o indivíduo se comportar, produzir, realizar e se inserir no mundo de forma adequada. O que sinto é o descompromisso, em grande parte do mundo da comunicação, com a questão educacional. Existem muitos exemplos, e a gente poderia se aprofundar, discutir: como na publicidade, trata-se uma situação grave, porque presta mais serviços ao mundo da economia do que à comunicação, quando deveria ser o contrário. Além do que deseduca, cria maus hábitos, passa informações incompletas ou inadequadas, gera comportamentos impróprios. Vivemos, hoje, um pouco do resultado disso. A comunicação e a educação exigiriam um entendimento muito claro. E quando falo sobre o mundo da comunicação, estou falando de tudo que se criou nessa infraestrutura imensa atual, que permite a informação chegar e, com ela, hábitos, comportamentos, modos de ver etc. As famosas novelas, a própria publicidade, as celebridades, a moda, enfim, uma infinidade de elementos apresentados através do mundo da comunicação. E sem compromisso com a educação, torna-se uma coisa absolutamente destrutiva para a sociedade. Para exemplificar, uma situação que gosto de citar para aprofundar: não adianta nada, em programas infantis matinais, induzir as crianças a um comportamento consumista, exagerado, e às vezes até voltado para determinadas atitudes que antecipam informações como, por exemplo, a educação sexual, e, à noite, escandalizar-se com o noticiário da exploração sexual infantil no país. Quer dizer, exagero um pouco essa reflexão para afirmar o seguinte: por que os meios de comunicação transmitem alguns valores e, mais tarde, os questionam, como se fosse um grande escândalo? E para ser um pouco mais duro com a emissora, digamos, mais hegemônica do país, afirmo que não adianta ela noticiar, escandalizada, que o país é tido como 
Sesc-SP: educação permanente, diversão garantida • Consuelo Ivo

exportador de prostitutas para o mundo inteiro, se faz propaganda do carnaval usando a figura de uma mulher negra, linda, sem roupas, rebolando na televisão! Os estrangeiros chegam aqui e dizem que isso não é possível, mesmo os dos países mais liberais. Você não vê isso lá em canais abertos. Se desejar, tem que recorrer aos canais pagos. Isso é deseducativo... Me desculpem, mas é deseducativo! As pessoas têm que perceber isso. Então, comunicação e educação têm um imbricamento profundo.

C\&E: Como essas questões são elaboradas na programação da TV Sesc?

Danilo: Tudo o que produzimos deve ter um componente educativo. Ainda há pouco, estava com uma professora da Escola de Comunicações e Artes da Universidade de São Paulo, a Lilia Amaral, e discutíamos sobre um livro que ela organizou juntamente com a professora Ana Mae Barbosa, também da

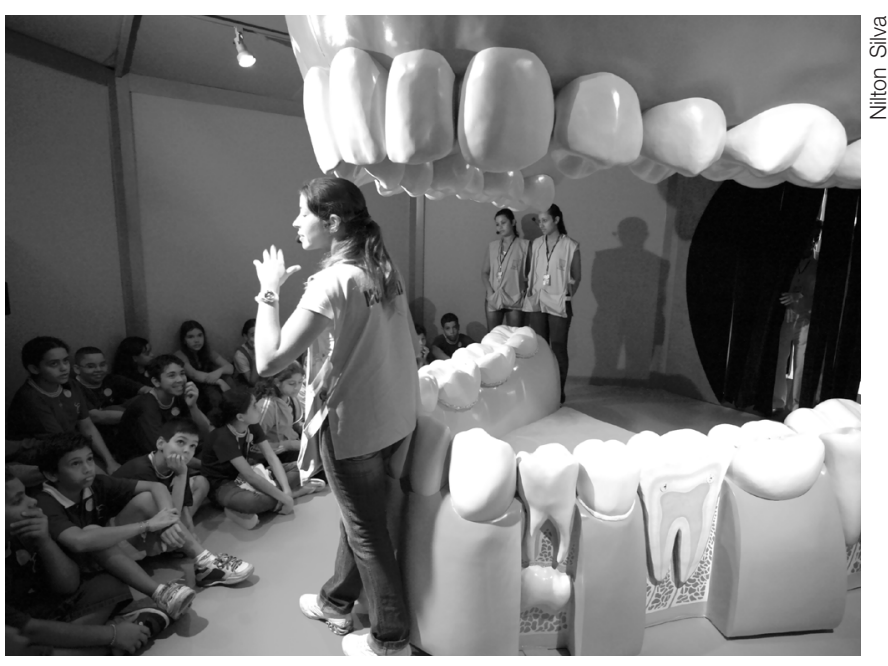

Exposição sobre saúde bucal na unidade de Interlagos. O projeto cenográfico contou com instalações interativas em $1.200 \mathrm{~m}^{2}$, contextualizada em quatro módulos. USP, e foi produzido pelo

Sesc/Senac. Nele, tratam da questão da interterritorialidade na arte, sempre sob o ponto de vista da educação. Na nossa revista da TV, a Revista E, o tempo todo discutimos, debatemos, propomos soluções. Não interessa fazer o que os outros fazem. Queremos sempre realizar na perspectiva educacional. E a TV Sesc também. Ela nasceu de forma um pouco suplementar. Era inicialmente um produto do Senac, para desenvolver questões do trabalho e da formação profissional, e fomos convidados para participar de algumas de suas ações. Envolvemo-nos com certos programas e já não discutíamos mais só assuntos de formação, mas da cultura, do acesso, da informação, da importância da atividade física para o bem-estar das pessoas, da saúde num sentido mais amplo etc. Até que acabamos por ficar com a TV, que hoje se chama TV Sesc, Canal Sesc ou Sesc TV. Ela é produzida junto com algumas instituições, como a TV Cultura, e outras organizações públicas, numa perspectiva também educativa. A nossa TV só tem sentido se cumprir essa missão. Nosso papel é criar um fluxo de informações, seja para o público interno, seja para o externo, através das nossas publicações, do nosso site, do nosso canal de TV. E essa missão é partilhada com os Sesc do Brasil inteiro.

C\&E: O público do Sesc reage de que forma a essa missão?

Danilo: Temos a informação de que muita gente frequenta o Sesc sem saber previamente a programação, porque confia em encontrar um programa de 
comunicação \& educação • Ano XIV • Número 2 • maio/ago 2009

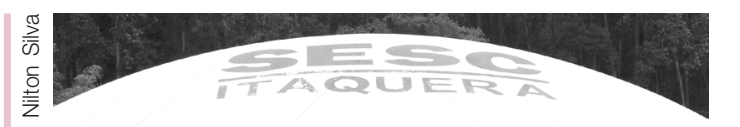

qualidade. As pessoas vão para o Cinesesc, para o Sesc Pompeia, ou Vila Mariana, enfim, vão com a família,

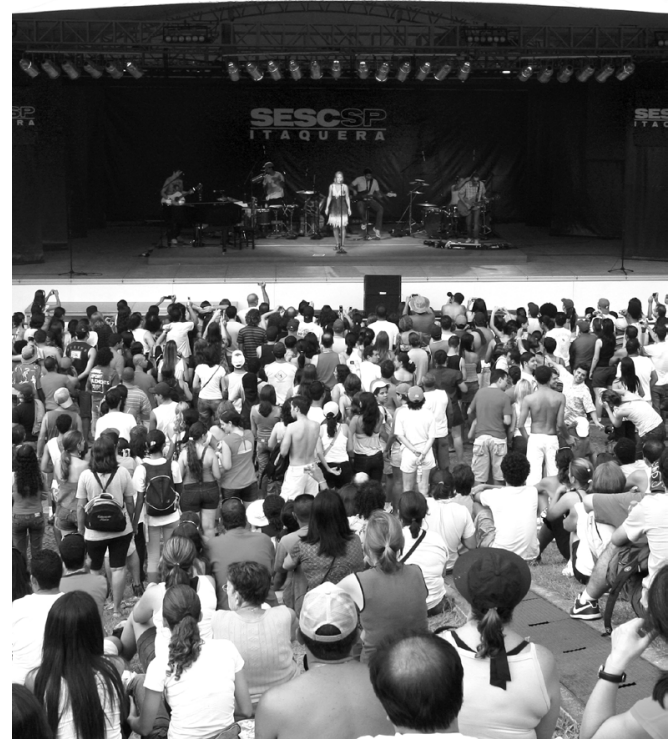
com as crianças, se alimentam por lá e sabem que vão encontrar alguma coisa, ou uma peça de teatro, ou uma exposição, música. Remonto um pouco ao passado e comparo com situações do presente que sinto falta, como a questão da territorialidade, do lugar. Antigamente tínhamos lugares aonde as pessoas iam sem programa, sem motivo, iam por ir. No interior ainda existe isso; por exemplo, as pessoas vão à praça para namorar, ver gente, bater papo, encontrar um amigo... Não importa. Vão por ir, porque é bom. A diversão é garantida, mas não existe mais essa característica nos Show da cantora Paula Toller na unidade de Itaquera, inaugurada em 1992 e com capacidade de atendimento de 15 mil pessoas/dia. grandes centros urbanos, porque faltam espaços, oportunidades... É raro isso. Entretanto, dois espaços mantêm ou fortalecem isso. Nós do Sesc procuramos criar, substituir, essa espécie de praça pública antiga. Ou seja, as pessoas vêm sem motivo, não porque sabem o que vai acontecer. Isso vale para as capitais e para o interior. O outro espaço é o dos shoppings centers. As pessoas vão também sem se importar com a programação. Vão porque é bonito, é seguro, é agradável, tem gente bonita. E a nossa classe média é um pouco assim. Isso remonta à praça pública da Idade Média. Com a invenção das cidades, as pessoas vão a esse espaço. É o espaço da diversão, da comunicação, do encontro, dos artistas de rua, do arauto do rei. Para uma instituição, ter a informação de que as pessoas a frequentam sem um compromisso de conhecer o que as espera é realmente um acontecimento extraordinário. Ela está cumprindo o papel de ser um polo, coisa que a escola no fim de semana poderia ser, como foi numa certa época; como a igreja foi com seu átrio. Mas tudo isso se confundia um pouco com o antigo espaço público das praças. Portanto, a escola e a igreja acabavam sendo uma extensão das praças. Elas promoviam o encontro de gerações. Há muitos pais que precisam cuidar dos filhos nos fins de semana, ou porque são separados, ou porque têm pouca oportunidade de estar junto com eles; enfim, são novas formações de família que o Sesc acompanha. Só para citar, instalamos fraldários nos banheiros masculinos. Ou seja, também falamos de espaços imaginados e adequados para novas funções, que não as determinadas anteriormente. Estamos atentos a tudo isso, ao cotidiano, sem nunca perder de vista as ações de educação informal e permanentes, com o intuito de valorizar os indivíduos ao estimular a autonomia pessoal, a interação e o contato com expressões e modos diversos de pensar, agir e sentir. 